\title{
Design Mobile Application of Marriage Counseling on the Catholic Church with UCD and Wireframe Method
}

\author{
Leonardus Ari Wardana ${ }^{1}$, Suyoto $^{2}$ and Pranowo ${ }^{3}$ \\ ${ }^{1}$ Master of Informatics Engineering, Universitas Atma Jaya Yogyakarta \\ Yogyakarta, 55281, Indonesia \\ ${ }^{2}$ Master of Informatics Engineering, Universitas Atma Jaya Yogyakarta \\ Yogyakarta, 55281, Indonesia \\ ${ }^{3}$ Master of Informatics Engineering, Universitas Atma Jaya Yogyakarta \\ Yogyakarta, 55281, Indonesia \\ ${ }^{1}$ leowardana@gmail.com, ${ }^{2}$ suyoto@mail.uajy.ac.id, ${ }^{3}$ pran@mail.uajy.ac.id
}

\begin{abstract}
The mobile application is an application that is growing very rapidly and gains broad market. One of its advantages is practical and easy to use everywhere. Although its development is quite rapid,its applications in the field of consultationis limited, especially in the field of consultation services organized by the Catholic Church.

This paper describes how to design mobile application counseling for the Catholic Church using User Centered Design (UCD) and Wireframe. The scope of the consultation material is about the marriage preparations. The research is conducted on marriage preparation classes in one of the Catholic Churches in Yogyakarta.

The results of the study, that is analyzed using ISO standardwith score average 4.425 andSystem Usability Scale (SUS) evaluation method with totalscore 82 showed that this study succeeded in designing a mobile application marriage counseling in the Catholic Church is consistent with user needs.
\end{abstract}

Keywords: Mobile Counseling, UCD, Wireframe, Mobile Counseling Application

\section{Introduction}

The development of mobile devices has been growing very rapidly. The presence of these devices has responded to the various needs of the community because it is practical and easy to use everywhere [HYPERLINK $\backslash 1$ "JAy14" 1 ]. The growths of mobile devices need to be supported by the development of applications that run on these devices. Mobile application development has become one of the sectors that is growing and growing [2-3].

There are many companies both local and globally such as facebook, twitter, and other research and development of mobile applications as part of the strategic planning. Several applications have been developed on the web platform, but its development in the future also supports mobile applications on its platform 4]\}.

The mobile device often experiences changes in attracting consumers and gaining a wider market, as well as the application platform, device, technology, features, network model, and the scope of its application. The speed of these changes should be carefully considered before making an investment or to make an application [HYPERLINK \ "Bal13" 5 ].

A wide variety of mobile applications developed in such fields as health, trade, education, consulting and others. Mobile applications in the field of consultation available at the moment are still very limited 6] $\}$ especially in the field of consultation services organized by the Catholic Church to his flock. 
Consulting services include a variety of life issues faced by the people and the way to overcome them.In practice, this consulting service has some limitations. Constraints of time, distance apart, and bustle of everyday make personal meeting between the counselor and the first people to talk about personal nature an important part of the system of counseling [ HYPERLINK $\backslash 1$ "Gka15" 2 ]. An implementation technology required to support the activities of this counseling service suits their needs and improves the services effectively and efficiently 7]\}.

Background of the issue required mobile application counseling to address problems faced. This application is expected to be the communication media between the client and the counselor so as to connect easily by means of mobile devices and the Internet network.The development effort required to create smartphone applications typically substantially [ HYPERLINK \l "Jai15" 8 ], many methods developed in order to produce an application that can meet the needs of users with good quality.In this study, the authors propose the design mobile application of marriage counseling on the catholic church with User Centered Design (UCD) and wireframe method.

UCD is one of the methods in the development of mobile application to generate an application in accordance with user needs. By basing the context of usability, a mobile application can be designed based on the model of UCD Processes 9]\}. From the context of usability, the application is designed based on 5 stages: identifying need, specifying the context of use, specifying requirements, producing design solutions, Evaluating design and implementation system. The production stage of the design solution and determined how an application designed. Another method that can be used is the wireframe. Wireframe is a method of interface design in the form of a page framework.

\section{Literature Review}

There are several previous studies that focus on designing mobile applications counseling. Table 1, summarized their studying with previous research.The purpose of this study was to design mobile applications wedding in the Catholic Church by using UCD and Wireframe.

Table 1. This Research and Previous Research Objectives

\begin{tabular}{|l|l|}
\hline Reserach & Objective \\
\hline Augar (2013) & $\begin{array}{l}\text { Developing an application counseling to promote } \\
\text { communication between children and parents } \\
\text { experiencing separation and has the potential to be } \\
\text { resolved in court [ HYPERLINK ll "Aug13" 10 ]. }\end{array}$ \\
\hline Salman (2015) & $\begin{array}{l}\text { Analysis and design of mobile applications to manage } \\
\text { the daily diet according to the nutritional needs of the } \\
\text { body. The design method carried out through four } \\
\text { stages: analysis, design, implementation, and } \\
\text { evaluation 11]\}. }\end{array}$ \\
\hline Kiili (2012) & $\begin{array}{l}\text { Designing a learning game app must attract and } \\
\text { integrate effectiveness based on the user experience. } \\
\text { The method developed is a block of flow experience [ } \\
\text { HYPERLINK } 1 \text { "Kii12" 12 ]. }\end{array}$ \\
\hline Lin (2011) & $\begin{array}{l}\text { Getting the overall evaluation of the participants on the } \\
\text { platform of e-Course is based on data collected } \\
\text { through questionnaires, interviews, and simulated } \\
\text { scenario 13]\}. }\end{array}$ \\
\hline Schmidt-Rauch (2014) & \begin{tabular}{l} 
Developing an application using the model m \\
\hline
\end{tabular}
\end{tabular}




\begin{tabular}{|l|l|}
\hline & $\begin{array}{l}\text { counseling UCD Process to provide added value in a } \\
\text { travel e-commerce system [ HYPERLINK V "Sch14" } \\
\text { 9 ]. }\end{array}$ \\
\hline Wong (2012) & $\begin{array}{l}\text { Developing a mobile application with user interface } \\
\text { design process models adopted from Pugh's PDP } \\
\text { (Product Development Process) 14]\}. }\end{array}$ \\
\hline Wong (2012) & $\begin{array}{l}\text { Developing user-centered products and user } \\
\text { experience by combining the design of UCD and UX } \\
\text { models [ HYPERLINK V "Won121" 15 ]. }\end{array}$ \\
\hline This Research (2016) & $\begin{array}{l}\text { Designing mobile applications marriage counseling to } \\
\text { the Catholic Church by using UCD and Wireframe. }\end{array}$ \\
\hline
\end{tabular}

\section{Theory}

\subsection{Mobile Application}

The mobile application is an application that runs on mobile devices. Mobile applications designed to run on a smartphone platform. Currently, there are a lot of marketplaces that provide a variety of mobile applications such as google playstore, Apple Apps Store and other marketplace 14]\}.This device has a relatively large storage media, a good performance and has a high data transfer rate [ HYPERLINK ll "Pau15" 16 ].

\subsection{User Center Design (UCD)}

UCD is a method of developing a software application or website that refers to the user. This method is used to ensure an application to be easy to use. The UCD processes the entire design phase to the application development life cycle 17]\}. UCD specifically consists of three basic principles of the focus on the user, empirical, and iterating [ HYPERLINK $\backslash$ "Won12" 14 ].

\subsection{Wireframe}

Wireframe is a method of user interface design shaped picture frame. The visual guide that represents the structure of a page in an application. Framework pages are created and developed based on user experience.

\subsection{E-Counseling}

E-counseling is counseling methods that use communication technologies such as telephone, internet and teleconference 18]\}.while mobile counseling is a counseling method that uses an application that runs on mobile devices such as smartphone.

\section{Methodology}

Stages of the study include several phases that are tailored to the phase at the UCD method with interface design method using wireframe. In detail the stages of this research can be seen in Figure 1. 


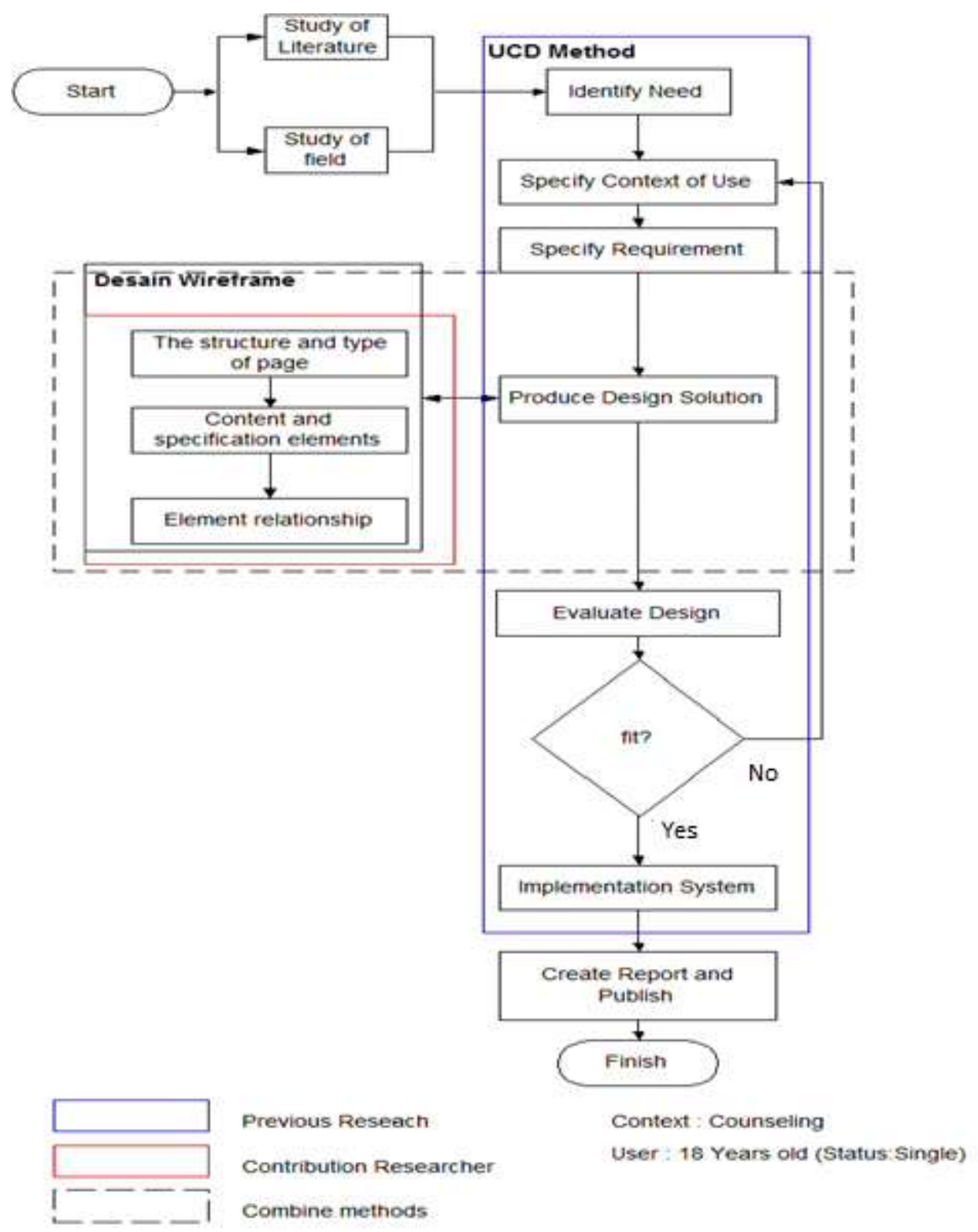

Figure 1. Flow Chart the Stages of Research

Stages of the study include several phases that are tailored to the phase at the UCD method with interface design method using wireframe. There are five stages in the UCD process, namely Identified Requirements, Specifications Context Use, Users and organizational Requirements Specification, Design Producing Solution, Evaluating Design and implementation. Wireframe on user interface design is used to design the display. This method consists of three phases that determine the structure and types of pages, determine the content and specifications of the element, and determine the relationship between elements.

Process design and interface design describe the design of physical and non-physical. Non-physical design is based on UCD process while the physical design is based on the design of the interface by using wireframe. 


\section{Design Mobile Counseling}

\subsection{Information Needs Analysis}

In this stage, the researchers identify the list of user needs through observation and interviews. Based on observations and interviews of users there is some information that is required for system design. The information required in counselingmobile applications for marriage problems are as follows:

1. Data of counselors

2. Data of member or client

3. Module ofmarriage preparation and problem solving (learning content)

4. List of questions

\subsection{Analysis of Functional Requirement}

System functional requirement for mobile application counseling for marriage problems are as follows:

1. System has the ability to connect the client and counselor through internet.

2. System has the ability to display a list of counselor and client list.

3 . System has the ability to displaya list of learning content.

4. System has the ability to displaya list of frequently asked issue.

5. System has the ability to connect the client and counselor through a private chat.

\subsection{Use Case Diagram}

Use case diagram is used to show the processes that are inside. Usecase mobile application counseling for the Catholic Church with UCD and wireframe method can be seen in Figure 2 .
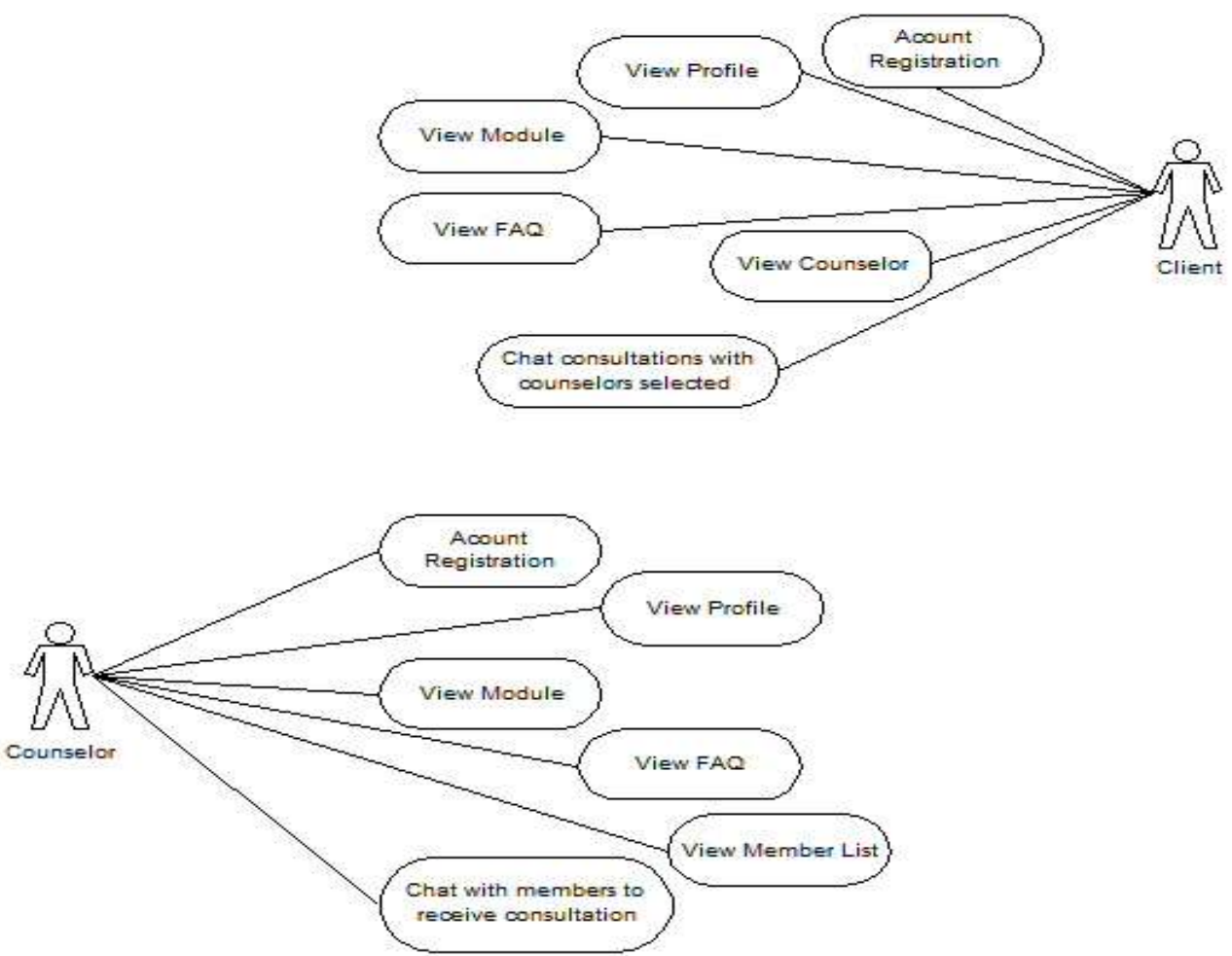

Figure 2. Use Case Diagram 


\subsection{Wireframe Design}

Wireframe design is an application interface design consulting. The design of this interface as detailed wireframe design can be seen in Figure 3.

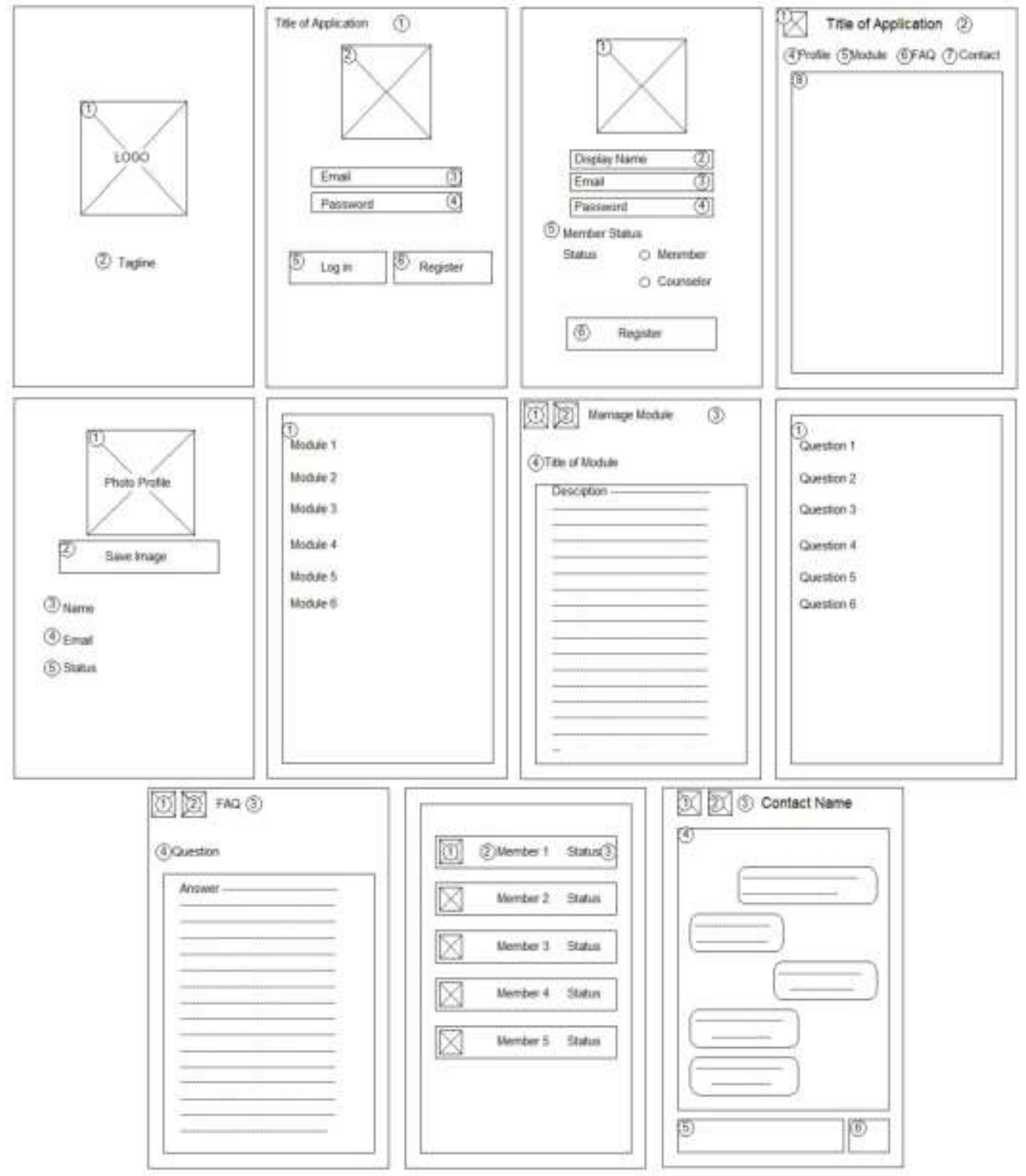

Figure 3. Wireframe Design

\section{Discussion and Result}

\subsection{Implementation}

Implementation is the stage of the steps being taken to implement the draft that has been made. Mobile app marriage counseling screenshot can be seen in Figure 4. 


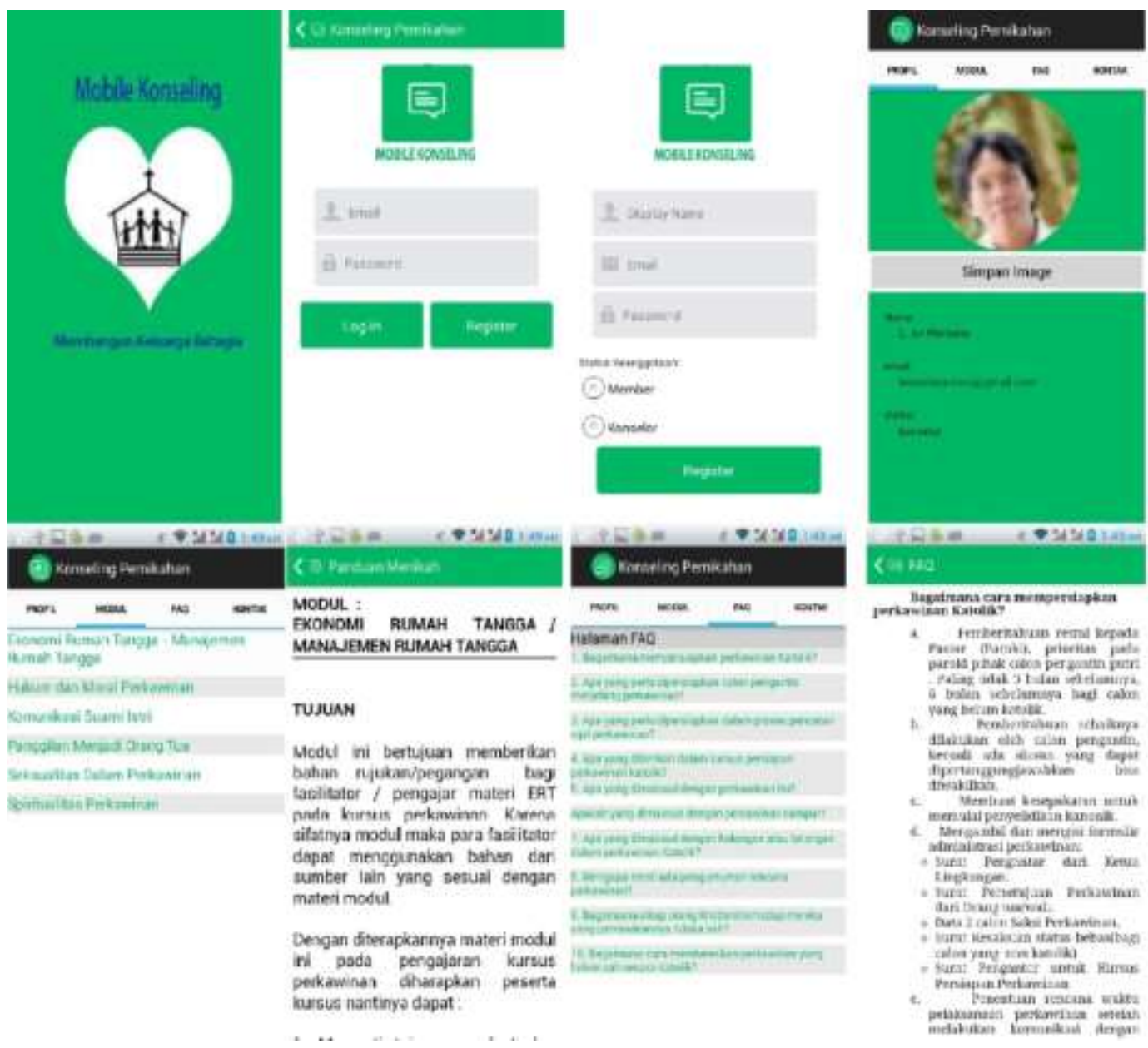

Figure 4. Screen Shoot of the Application

\subsection{Evaluation}

The mobile application marriage counseling is evaluated in 20 class participants' pre-marriage courses. The participants use this application to conduct counseling in order to prepare for her marriage. After using this application, participants gave feedback based on the evaluation method ISO standard and System Usability Scale (SUS).

Evaluation using ISO standards emphasizes the criteria of effectiveness, efficiency and satisfaction. The System Usability Scale (SUS) refers to the feeling of the user as an expression of the experience of using the application [ HYPERLINK $\backslash 1$ "Ban09" 20 ]. Table 2, shows the results of evaluation by using the ISO standard.The evaluation results indicate an application to get the score 4.425 of scale 5 .

Table 2. ISO Standart Evaluation

\begin{tabular}{|l|l|l|}
\hline No. & Indicator & Score \\
\hline 1 & Application is easy to use & 4.25 \\
\hline 2 & $\begin{array}{l}\text { Applications can provide information on marriage preparation } \\
\text { module }\end{array}$ & 4,25 \\
\hline 3 & $\begin{array}{l}\text { The system can provide information counselor / Member of } \\
\text { existing }\end{array}$ & 4.5 \\
\hline
\end{tabular}




\begin{tabular}{|c|c|c|}
\hline 4 & $\begin{array}{l}\text { The system can connect between the counselor and the } \\
\text { members (member) through the chat }\end{array}$ & 4.24 \\
\hline 5 & Features / functions of the application runs well & 4.25 \\
\hline 6 & Display guide materials (modules) married readable & 4.75 \\
\hline 7 & $\begin{array}{l}\text { Display a list of questions and answers (FAQs) can provide } \\
\text { information that is clear enough }\end{array}$ & 4.75 \\
\hline 8 & $\begin{array}{l}\text { Display features / functions of chatting between counselor and } \\
\text { member (member) goes well }\end{array}$ & 4.5 \\
\hline 9 & The size and typeface on the application is clearly legible & 4.5 \\
\hline 10 & These applications run stable / smooth & 4.25 \\
\hline & Average & 4.425 \\
\hline
\end{tabular}

The second evaluation is done using SUS. Table 3, shows the results of evaluation by using SUS.The evaluation results using SUS indicates that the score was 82 out of 100 .

Table 3. SUS Evaluation

\begin{tabular}{|l|l|r|}
\hline No. & Indicator & Score \\
\hline 1 & I think that this app will be useful / frequently used. & 3,6 \\
\hline 2 & I think that this app is quite complex & 3,2 \\
\hline 3 & I think that this app is easy to use & 3,8 \\
\hline 4 & I thought that I would need help from others to use this app & 3,8 \\
\hline 5 & $\begin{array}{l}\text { I found that the functions / features in this application } \\
\text { integrates well }\end{array}$ & 3,4 \\
\hline 6 & $\begin{array}{l}\text { I think that there are many components in the improper } \\
\text { application of the layout. }\end{array}$ & 3,8 \\
\hline 7 & $\begin{array}{l}\text { I imagine that many people will be easy to learn and use the } \\
\text { application quickly. }\end{array}$ & 4 \\
\hline 8 & I saw this app awkward to use & 3,2 \\
\hline 9 & I feel very confident using this application. \\
\hline 10 & $\begin{array}{l}\text { I need to learn a lot of things before you can utilize this } \\
\text { application. }\end{array}$ & 3,6 \\
\hline & \multicolumn{2}{|c|}{ Total Score Score } \\
\hline
\end{tabular}

\section{Conclusion}

Mobile application of marriage counseling on the Catholic Church has been designed to meet the aims and objectives of this research using the UCD and wireframe method. This system can easily be used by the user as a participant in the course of counseling. This system has been in accordance with its function and fulfills user needs in preparation for marriage counseling.

The results of the study, that is analyzed using ISO standard with score average 4.425 and System Usability Scale (SUS) evaluation method with total score 82showed that this study succeeded in designing a mobile application marriage counseling in the Catholic Church is consistent with user needs. 


\section{References}

[1] J. A. Oluwafemi, "Mobile - Health Application Software Design and Development," , (2014), pp. 59-67.

[2] V. Gkatzidou, K. Hone, L. Sutcliffe, J. Gibbs, S. T. Sadiq, A. Szczepura, P. Sonnenberg and C. Estcourt, "User interface design for mobile-based sexual health interventions for young people: design recommendations from a qualitative study on an online Chlamydia clinical care pathway", BMC medical informatics and decision making, , (2015), pp. 72.

[3] N. O. Keskin and A. Kuzu, "Development and testing of a M-learning system for the professional development of academics through design-based action research," International Review of Research in Open and Distance Learning, (2015), pp. 193-220.

[4] R. Ferdiana, "Agile Software Engineering Framework for Evaluating Mobile Application Development”, International Journal of Scientific \& Engineering Research, (2012), pp. 1-5.

[5] N. Balasupramanian, R. Lakshminarayanan and R. D. Balaji, "Software Engineering Framework using Agile Dynamic System Development Method for Efficient Mobile Application Development”, (2013), pp. 126-135.

[6] J. E. A. Okech and M. Kimemia, "Professional Counseling in Kenya: History, Current Status, and Future Trends", Journal of Counseling and Development, (2012), pp. 107-112.

[7] F. Spielberg, A. Kurth, W. Reidy, T. McKnight, W. Dikobe and C. Wilson, "Iterative evaluation in a mobile counseling and testing program to reach people of color at risk for HIV-new strategies improve program acceptability, effectiveness, and evaluation capabilities", AIDS Education and Prevention, (2011), pp. 110-116.

[8] A. Jain, J. Adebayo, E. De Leon, W. Li, L. Kagal, P. Meier and C. Castillo, "Mobile Application Development for Crisis Data", Procedia Engineering, (2015), pp. 255-262.

[9] S. Schmidt-Rauch and G. Schwabe, "Designing for mobile value co-creation-The case of travel counselling”, Electronic Markets, (2014), pp. 5-17.

[10] N. Augar and J. Zeleznikow, "Developing Online Support and Counseling to Enhance Family Dispute Resolution in Australia", Group Decision and Negotiation, (2013), pp. 1-18.

[11] A. G. Salman, S. R. Manalu, N. Chandra and A. P. Gomis, "Analysis and Design for Food Planning Mobile Application", Procedia Computer Science, (2015), pp. 275-281.

[12] K. Kiili, S. D. F. Arnab and L. T. Sylvester, "The design principles for flow experience in educational games”, Procedia Computer Science, (2012), pp. 78-91.

[13] C. H. Lin, I. C. Lin and J. S. Roan, "To evaluate interface usability of an e-course platform: User perspective", African Journal of Business Management, pp. 196-202, 2011.

[14] C. Yin, W. C. Khong and K. Chu, "Interface Design Practice and Education Towards Mobile Apps Development", Procedia - Social and Behavioral Sciences, (2012), pp. 698-702.

[15] M. L. Wong, C. W. Khong and H. Thwaites, "'pplied UX and UCD Design Process in Interface Design", Procedia - Social and Behavioral Sciences, (2012), pp. 703-708.

[16] N. Paulins, S Balina and I. Arhipova, "Learning content development methodology for mobile devices," Procedia Computer Science, vol. 43, no. C, (2015), pp. 147-153.

[17] K. Leichtenstern, E. André and R. Matthias, "Tool-Supported User-Centred Prototyping of Mobile Applications", International Journal of Handheld Computing Research, (2011), pp. 1-21.

[18] E. A. Kolog, E. Sutinen and M. Vanhalakkka-Ruoho, "E-counselling implementation : Students ' life stories and counselling technologies in perspective", IJEDICT (International Journal of Education and Development using information and Communication Technology), vol. 10, no. 3, (2014), pp. 32-48.

[19] JohBrooken, "SUS : A Retrospective," Journal of Usability Studies, (2013), pp. 29-40.

[20] A. Bangor, P. Kortum and J. Miller, "Determining what individual SUS scores mean: Adding an adjective rating scale", Journal of usability studies, (2009), pp. 114-123.

\section{Authors}

Leonardus Ari Wardana, Ari Wardana is a priest of the Catholic Church who are completing graduate studies in the department of informatics engineering Atma Jaya University, Yogyakarta. Focus research on mobile applications in the field of marriage counseling to facilitate service to the people.

Prof. Ir. Suyoto, M.Sc., Ph.D., Suyoto is Professor in Department of Informatics Engineering at University of Atma Jaya Yogyakarta, Indonesia. He has more than ten years of teaching experience. Here ceived his $\mathrm{PhD}$ from the National University of Malaysia, Malaysia. His research interests are multimedia, computer graphics, visualization, mobile application and artificial intelligence. 
International Journal of $u-$ and $\mathrm{e}-$ Service, Science and Technology

Vol. 10, No. 1 (2017)

Dr. Pranowo, S.T., M.T., Dr.Pranowo is lecturer in Department of Informatics Engineering at University of Atma Jaya Yogyakarta, Indonesia. He has more than ten years of teaching experience. His research interests are computer graphics and soft computing 